\title{
THINKING ABOUT A UNIFIED, PLANNING-BASED PROJECT CONTROLS ENVIRONMENT
}

\author{
C. WILLIAM IBBS \\ Associate Professor \\ Department of Civil Engineering \\ University of California \\ Berkeley, CA 94720
}

\section{SUMMARY}

Adaptation of new and exciting computer technologies such as knowledgebased systems (KBS), object-oriented databases (OODB's), and robotics will dramatically alter projects. The premise of this paper is however that we need to re-think how many of these automation technologies should be developed and inter-related. A generalized core theory is vital for bringing cost, schecule and affiliated control systems together earlier in the project. Ideally this unification would happen during the conceptual planning phase.

This discussion first reviews the way that CAD-level information is today being relied upon to serve as a unifying agent. Most recent work presumes that a detailed design representation exists upon which various project control systems can be predicated. However development of a CAD representation occurs too late in the project development process to support meaningfully useful planning. That is, CAD-based project control tools are generally insufficient for turnkey projects. The answer then is a suite of tools that relies upon a planning-oriented information base. This paper discusses the current thinking by the author about the conceptual comporients and mecinanics of such a system. Parallels are drawn to the work packaging concept. An object-oriented paradigm is currently the tool with which these icieas are being tested.

KEYWORDS: COMPUTERS, CONSTRUCTION, CONSTRUCTIONMANAGEMENT, DATABASES, OBJECT-ORIENTED FROGRAMMING, PROJECT CONTROLS, PROJECT MANAGEMENT, WORK PACKAGE

\section{THE ROLE OF PROJECT PLANNING}

Many people have cited the critical value of good, early planning and its effect on project success. Figure 1 is an adaptation of the Level of Influence diagram [Paulson]. This schematic illustrates that decisions taken early in the project have 


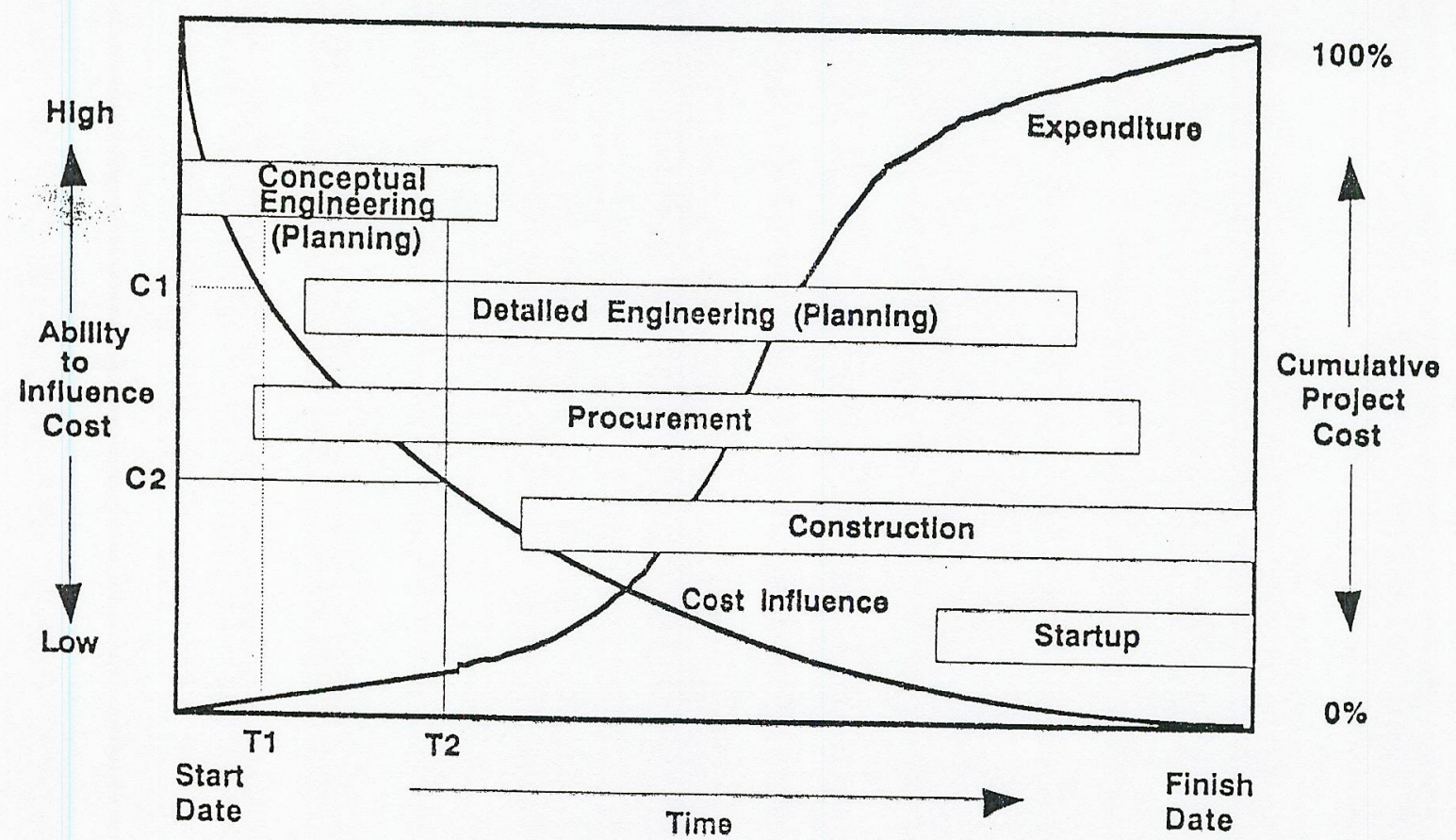

Figure 1. Level of Influence Concept

tremendous impact on downstream construction operations and facility operation efficiencies. One elaboration on this figure is the addition of a discrete, separate conceptual planning function. This is an intense function that is undertaken by high-level, experienced project management personnel. It of course sets the general tone and execution strategy for the job.

A second enhancement is an overlay of the reference point pairs $\mathrm{C}_{m}-\mathrm{T}_{n}$. Our purpose in doing this is to demonstrate that the level of influence is affected even by the timing of decision making in the Planning phase itself. Usually the generalized form of this figure is used to demonstrate the incremental value of decisions between the design, construction and operations phases. Here we argue that there is necessarily a difference within the initial planning stage alone.

These observations are critical to the nature of current automation research because many of our current investigations presuppose the existence of a detailed CAD representation. For instance, PLANEX [Zozaya-Gorostiza], PLATFORM [Levitt], CRITEX [DeLaGarza], SUPR [Grobler], SIPE [Kartam] and PREPLANNER [Echeverry] are contemporary knowledge based systems developed to support project control practice. Yet they all utilize specific design information as a basis for scheduling or costing. The key question then is how can these tools really be of value as planning aids before detailed design is 
complete. Clearly the answer is that they can not.

Expressed another way, computer-based planning tools must be developed that can function without the existence of specific information about the design of the project under study. Accordingly, the next important strategic wave of research needed is idea generation, concept refinement and model development that support project controls analysis with only planning-level information.

\section{THE PROJECT PLANNING PROCESS}

Understanding the decisions, information and procedures that constitute the planning phase is a logical first step to building automation support tools. Others [Kerridge; Barrie] have discussed the planning phase in more detail than space allows here. Just a few of the primary activities of concern for researching a new project controls environment are definition of: work scope, budget, schedule, contract delivery system, risk position, personnel and organizational staffing, and financing.

One trait that stands out in the planning process as such is that it is an interative, cyclic operation. Along with these iterations is information abstraction, aggregation, decomposition, collection, storage and transmittal being some of the discrete mental and physical steps to the process. Of particular interest to this research are the first 3 steps of abstraction, aggregation and decomposition.

Another general characteristic of this project development stage is the necessity of incorporating different people with varying views and agendas. For instance, designers tend to see the project as systems with behavior, configurational geometry, topology ard function. Constructors, on the other hand, while also interested in geometric and topological characteristics, must track commercial detalls such as pricing and delivery terms as well. The result is that to develop any muiti-faceted data system, a premium must be placed on the perspectives of the difierent pecple using the information at different times.

\section{PROJECT INFORMATION FLOW}

This information flow is partially represented in the pseudo-Entity/Relationship schematic of Figure 2. (A more fcrmal E/R description would depict the cyclicality of the process.)

Convention calls for the development and use of work packages at the earliest part of the project to model the evolutionary process of project development, and to assign responsibilities for each part of the job. Decomposition and aggregation are prime operators here. These work packages ideally are well- 


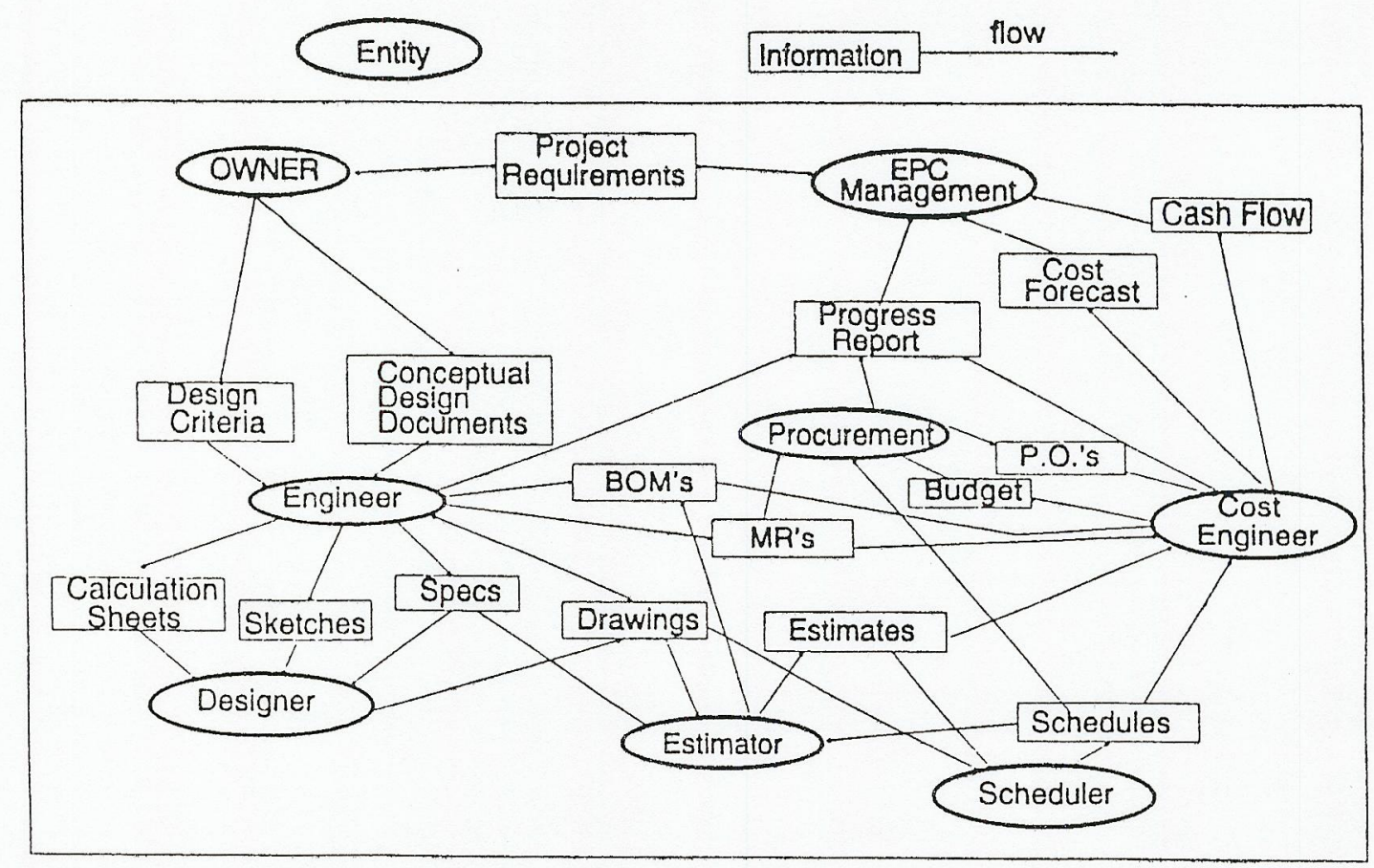

Figure 2. Information Flows During Planning Phase

defined scopes of work terminating in a deliverable product or completion of service. Packages may vary in size and timing, but should be a measurable and controllable unit of the project. One or more work tasks might constitute a work package with one or more groups of people (design squads, construction crews) involved. [CII]

Figure 3 illustrates our generic notation for a work package, and Figures 48 detail examples at each of 4 planning-design-construction project phases. Note in this example that the project phase is identified along with a characteristic goal of the work packaging definition effort. Also there is a narrative definition of the statement of work, and other parametric information such as estimate type and forecasted cost. Figure 8, just for purposes of example, shows a different type of aggregation/decomposition; namely one of instantiation by work type rather than project phase type.

There can also be a pointer in each work package that provides us with a link to the related work packages at the next phase. This particular representation is hierarchical in nature, the most common occurrence in construction. For instance there is a package for planning that scopes the functional needs (Figure 4) and 5 pointers to 5 work packages in the preliminary design stage. For the preliminary design stage there is a series of tagged detailed work pages and so 

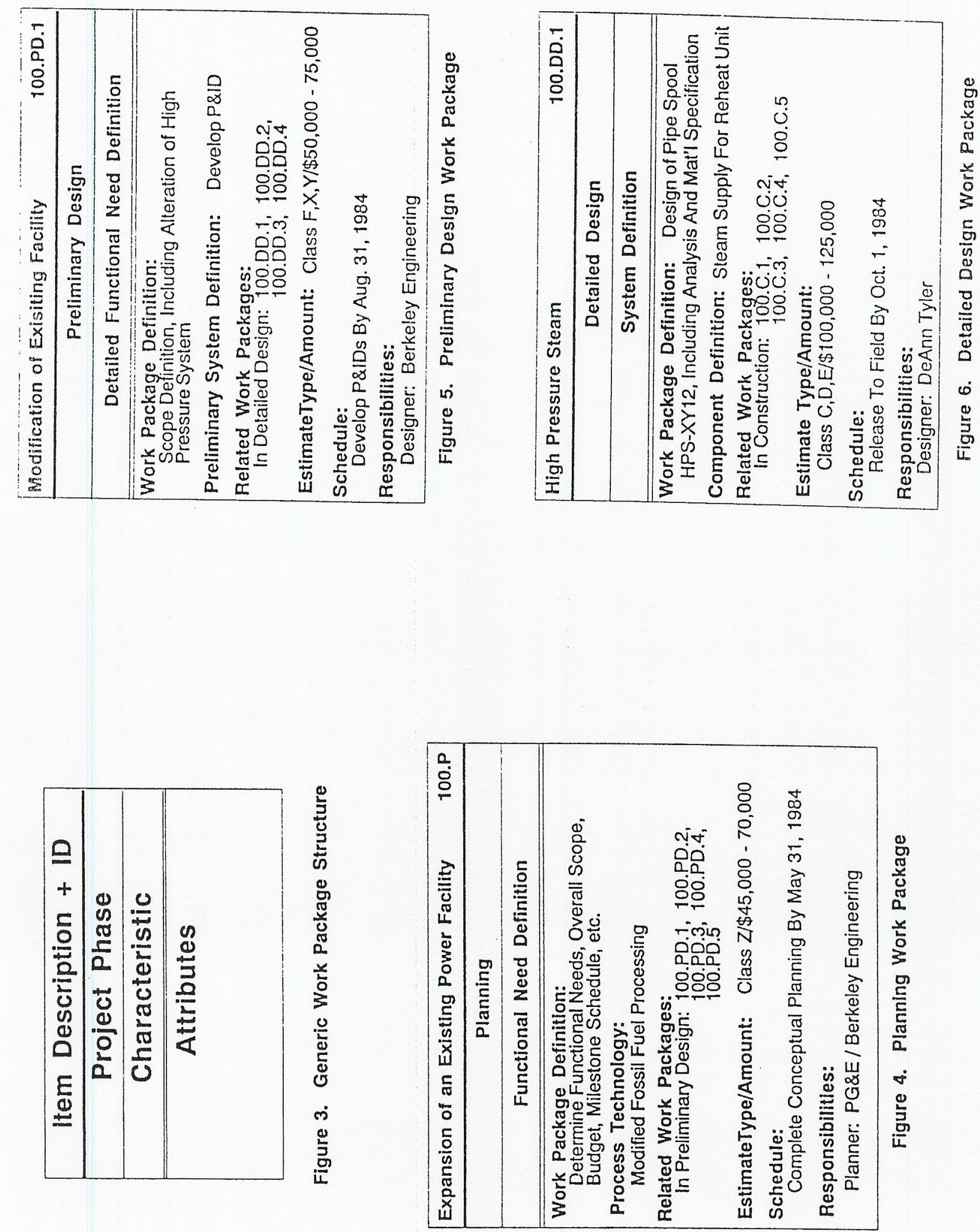


\begin{tabular}{|c|}
\hline Piping Erection \\
\hline Construction \\
\hline Component Installation \\
\hline Work Package Definition: \\
Install Spool HPS-XY12-L110 \\
Crew/Equipment Definition: P/F-4 \\
Estimate Type/ Amount: Class A,B/\$110,000 \\
Schedule: Start Nov. 7, 1984 \\
Finish Jan. 13, 1985 \\
Responsibilities: \\
SUPT: Zachary Tyler \\
\hline
\end{tabular}

Figure 7. Construction Work Package

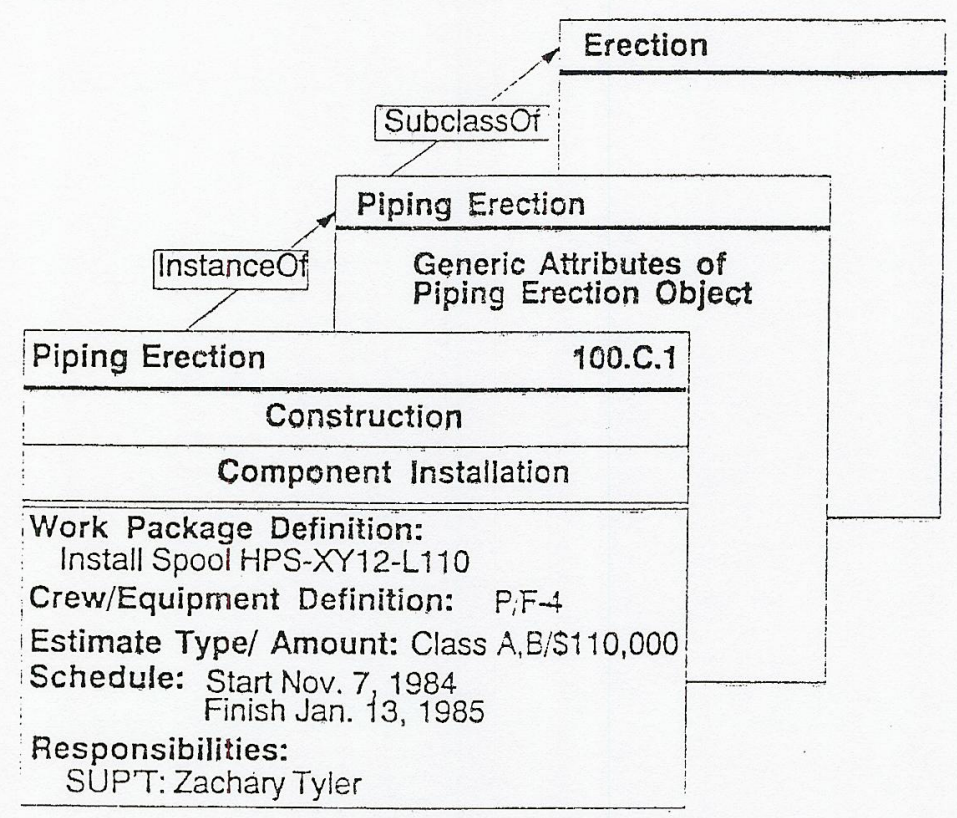

Figure 8. Work Package Instantiation

on. At each level we refine more precisely information that is needed to control that work package. This then conveniently provides us with a paradigm by which we can develop unified planning-based system for project control. What is lacking is the ability to capture the processes by which we can extrapolate approximate, planning information into scenarios of richer detail.

\section{WORKING TOWARD A UNIFICATION MODEL}

If indeed the work package concept does provide a useable beginning, and if the processes are a necessary addition to the current representation form, how 
might we go about adding this feature to enhance the total information model?

Figure 9 represents one direction for answering this question. This approach favors an object-oriented data management system because of the messagepassing and inheritance features available with that technology. A object unification scheme is crucial to the success of this model, meaning that there would be the capability to slice the project time continuum as desired. This differs from the current work package-driven model where slices are prescribed and strictly limited to specific points in time.

In this proposal advantage can be taken of existing data representations with certain extraction or filtering procedures, most of which will probably be heuristic. One research and development tactic might be to develop on-line reference libraries for particular industrial types. Then for an aluminum plant we can rely upon a cost-capacity factor relating total installed cost to facility output. That, of course, is a time-proven estimating method to a certain degree of accuracy and when there is historical experience with that plant type.

What seems more interesting and vital from a system automation perspective is to devote research effort to defining the nature of the objects, their classes and class structure and the links for this model. An initial key question then is what are the semantic relationships--or in other terms, what is the grammar that allows us to extend from known to unknown plant types.

Related but large enough to deserve special attention is the matter of how do we define "boundary conditions" for our semantic model. When, for instance, is a distillation process best served by a settling tank versus an agitating mechanism? Capacity levels and thermodynamic, chemical properties are important aspects of this decision; that is our system must have some deep knowledge characteristics.

Finally, there is also the broad issue of probabilistic representation. Being able to reason about uncertainty is a research field that is just beginning to take form. Qualitative reasoning, with fuzzy logic principles for example, is a powerful mechanism that seems appropriate [Chang]. Hypothetical reasoning is a tool that is worthy of exploration along with qualitative reasoning. In combination they would afford researchers the opportunity to handle the variability so common in projects like this.

\section{SUMMARY}

With this paper we have tried to ask questions and provoke thought about future research and development efforts for project control systems, be they estimating, cost, schedule, quality, saiety or whatever type of control. In the 


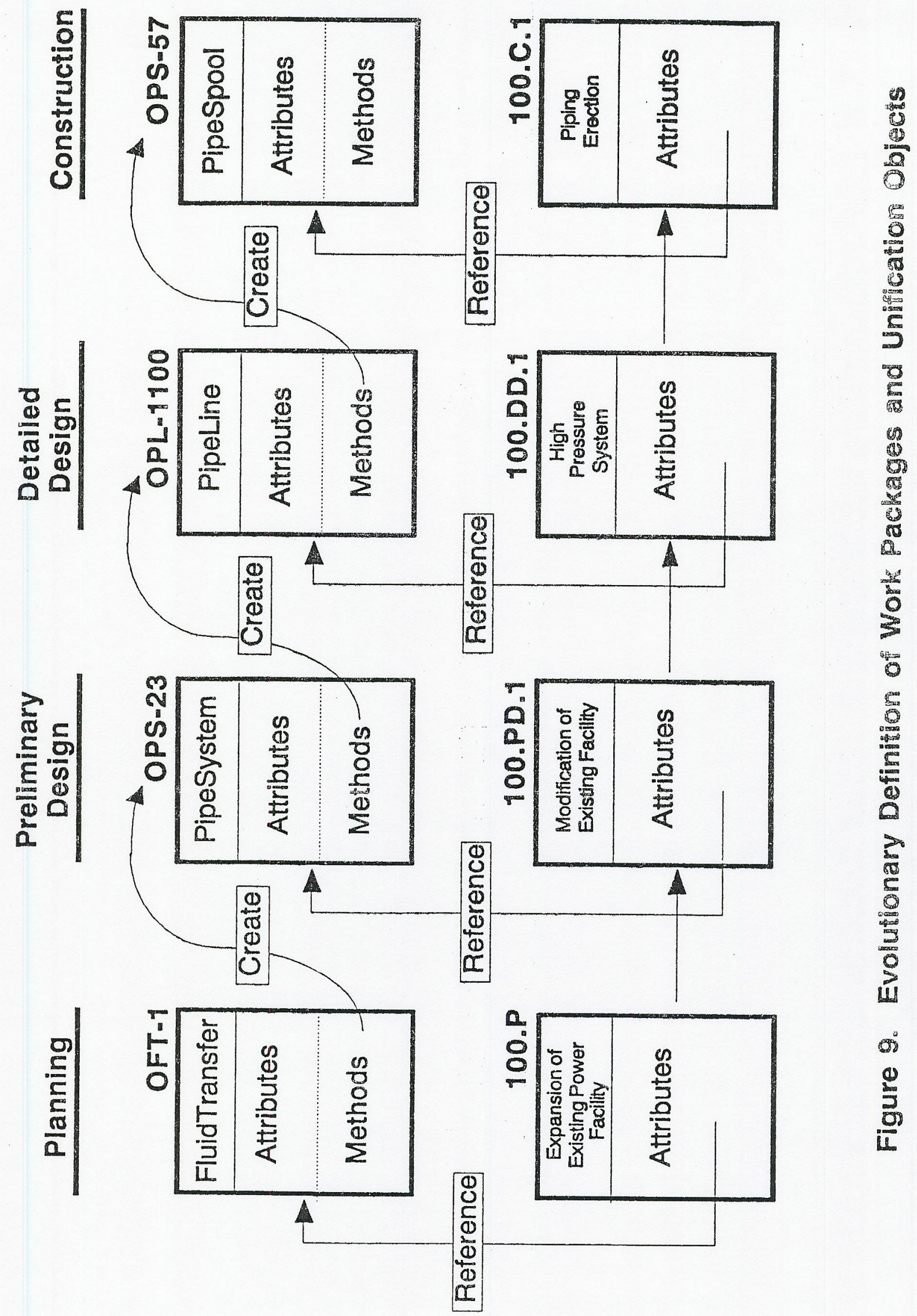


computer-aided design world major accomplishments are being realized in horizontal integration of disciplines; e.g. structural and mechanical engineering. There is reason for optimism, and definitely a need for vertical integration of the project development cycle. The work described in this paper outlines the current thinking of this author in linking the various project control functions along a time line.

Adapting the work project concept to an object-oriented representation has strong appeal. With a representation that automates the generation of the project continuum rather than only provides slices of that spectrum, our planning process will be enriched. The key will be not just coding certain physical components and traditional construction activities in object form. Rather, the major task is define how the object unification process transpires.

\section{REFERENCES}

BARRIE 1984 Barrie, D.S. and B.C. Paulson, Jr. Professional Construction Management. 2nd edition, McGraw-Hill, 1984.

CHANG 1990 Chang, T.C., C.W. Ibbs and K.C. Crandall, "Network Resource Allocation with the Support of a Fuzzy Expert System," scheduled for publication in the ASCE Journal of Construction Engineering and Management. June 1990, 27 pages.

CII 1987 Construction Industry Institute, Work Packaging for Project Control. CII Report \#6-7, 1987.

DELAGARZA 1990 DeLaGarza, J.M. and C.W. Ibbs, "A Knowledge Elicitation Study in the Construction Scheduling Domain" scheduled for publication in the ASCE Journal of Computing in Civil Engineering. June 1990, 23 pages.

ECHEVERRY 1989 Echeverry, D., C.W. Ibbs, and S. Kim; "Generation of Construction Schedules: A Knowledge-based Approach", Proceedings of the 6th International Symposium on Automation and Robotics in Construction. pp. 220227.

GROBLER 1988 Grobler, F. Object-oriented Data Representation for Unified Construction Project Information. Ph.D. dissertation, University of Illinois, UrbanaChampaign, August 1988.

KARTAM 1989 Kartam, N.A. Investigating the Utility of Artificial Intelligence 
Techniques for Automatic Generation of Construction Project Plans. Ph.D. dissertation, Stanford University, August 1989.

KERRIDGE 1986 Kerridge, A.E. and C.H. Vervalin, Engineering and Construction Project Management. Gulf Publishing, 1984.

LEVITT 1985 Levitt, R.E. and J.C. Kunz, "Using Knowledge of Construction and Project Management for Automated Schedule Updating." Project Management Journal 16 (5), pp. 57-76.

PAULSON 1976 Paulson, Jr. B.C., "Designing to Reduce Construction Costs," Journal of the Construction Division, ASCE. vol. 102, no. CO4, December 1976, p. 588.

Zozaya-Gorostiza 1988 Zozaya-Gorostiza, C., C. Hendrickson, D. Rehak and P. Lim, "A Knowledge Intensive Planner for Construction Projects," Proceedings of the 5th International Symposium on Robotics in Construction. Tokyo, 1988. 